\title{
The Possibilities of Paper Sludge Waste (PSw) Utilization in Cement Materials ${ }^{\dagger}$
}

\author{
Vilma Banevičienè ${ }^{1}$, Jurgita Malaiškienè ${ }^{1, *}$, Marija Vaičienè ${ }^{2}$ and Renata Boris ${ }^{1}$ \\ 1 Laboratory of Composite Materials, Vilnius Gediminas Technical University, Linkmenu str.28, \\ 08217 Vilnius, Lithuania \\ 2 Civil Engineering Faculty, Vilnius College of Technologies and Design, Antakalnio st. 54, \\ 10303 Vilnius, Lithuania \\ * Correspondence: jurgita.malaiskiene@vgtu.lt; Tel.: +370-5-251-2329 \\ + Presented at Innovations-Sustainability-Modernity-Openness Conference (ISMO'19), Bialystok, Poland, \\ 22-23 May 2019.
}

Published: 4 July 2019

\begin{abstract}
The paper production is developed throughout the world, therefore, more paper sludge waste (PSw) is accumulating. The aim of this work was to determine the properties of PSw burned at $900{ }^{\circ} \mathrm{C}$ and its impact on physical-mechanical properties of cementitious matrix and evaluate its usage/utilization possibilities in cementitious materials. For the implementation of the aim, cementbased specimens were prepared and their-mechanical properties were determined. Specimens from five compositions were formed, with $2.5 \%, 5 \%, 7.5 \%$, and $10 \%$ of the cement by weight replaced with PSw. When $5 \%$ of the cement was replaced with PSw, the compressive strength increased by approximately $7 \%$, although density and ultrasound velocity slightly decreased (up to $1.5 \%$ ). When $7.5 \%$ PSw was added, the compressive strength of the specimens decreased. To summarize, it can be stated that up to $5 \%$ PSw may be utilized/used for the preparation of cementitious mixtures. The usage of the waste allows environment conservation, reduced amount of cement in mixtures, and improvement of properties of cementitious materials.
\end{abstract}

Keywords: paper sludge waste; microstructure; XRD; strength

\section{Introduction}

The rational usage of industrial waste is a major challenge in implementing the provisions of the Circular Economy Documentation and ensuring the concept of cleaner production when it comes to increasing production efficiency and reducing the risk to humans and the environment. Therefore, the rational recycling of industrial waste is becoming a major challenge. As part of waste recycling and recovery programs, some natural materials will have to be replaced with waste in the future, including in the construction sector. Recycling of paper consumes $28 \%-70 \%$ less energy, than primary paper production and reduces emissions by $95 \%$, and saves water and raw materials. When paper decomposes, methane gas is released, which is 20 times more potent than $\mathrm{CO}_{2}$ when it comes to greenhouse processes [1]. In order to reduce methane $\left(\mathrm{CH}_{4}\right)$ emissions, products based on new materials and industrial waste are being developed.

Paper production is developed around the world and, every year, the production scale intensifies and more waste is generated. Paper sludge waste (PSw) is a multi-species waste produced at different stages of production, it is classified as harmless by the European Waste List, and its industry is widely developed worldwide. The recycling of cellulose and waste from the paper industry has great environmental benefits by preventing soil and water pollution. Scientists are constantly looking for ways to at least partially replace the most popular binder, which is Portland cement. Partial replacement of cement and lime with industrial waste is a widely explored area [2]. 
There are a number of studies where scientists use paper waste in concrete [3], clinker production [4], mortars [5], lightweight cement mortars [6], ecological geopolymer mortars [7], geopolymeric binders and mortars [8], and ceramic materials [9].

The aim of the work is to determine the properties of PSw burnt at $900{ }^{\circ} \mathrm{C}$ and its impact on the physical-mechanical properties of cement matrixes and to evaluate the utilization possibilities of this waste in cement materials.

\section{Materials and Methods}

In this research, cement CEM I 42.5 R was used. It was mixed with PSw. First, the PSw was dried at $75{ }^{\circ} \mathrm{C}$ temperature for $48 \mathrm{~h}$, then crushed and sieved through a $1 \mathrm{~mm}$ sieve. The chemical composition of dried PSw is provided in Table 1. The prepared PSw was burned at $900{ }^{\circ} \mathrm{C}$ and kept at this temperature for $2 \mathrm{~h}$. The waste was added in the form of dry white powder. X-ray analysis of PSw showed that the main ingredients included gehlenite $(G)$, calcium oxide $(C)$, alite $(A)$, and belite (B). Thermal analysis of PSw showed two main endo-effects which arose from burning it at $1000^{\circ} \mathrm{C}$ (Figure 1). At $\sim 352^{\circ} \mathrm{C}$, the crystal hydrates disintegrated, the connected water was liberated, and the specimen lost $16 \%$ of its mass. At $\sim 765^{\circ} \mathrm{C}$, the calcium carbonate decomposed to $\mathrm{CaO}$ and $\mathrm{CO}_{2}$. It was determined that burnt PSw significantly changed its mineral composition compared with dried PSw.

Table 1. Chemical composition of paper sludge waste (PSw).

\begin{tabular}{ccccccccccc}
\hline C_O(org) & $\mathrm{CaO}$ & $\mathrm{SiO}_{2}$ & $\mathrm{Al}_{2} \mathrm{O}_{3}$ & $\mathrm{Fe}_{2} \mathrm{O}_{3}$ & $\mathbf{M g O}$ & $\mathrm{TiO}_{2}$ & $\mathrm{SO}_{3}$ & $\mathrm{Cl}$ & $\mathrm{Na}_{2} \mathrm{O}$ & Others * \\
\hline 34.08 & 58.21 & 3.48 & 2.36 & 0.52 & 0.64 & 0.10 & 0.18 & 0.06 & 0.09 & 0.28 \\
\hline
\end{tabular}

*Others: Slight amounts of $\mathrm{P}_{2} \mathrm{O}_{5}, \mathrm{~K}_{2} \mathrm{O}, \mathrm{MnO}, \mathrm{NiO}, \mathrm{CuO}, \mathrm{ZnO}, \mathrm{SrO}$, and $\mathrm{ZrO}_{2}$.

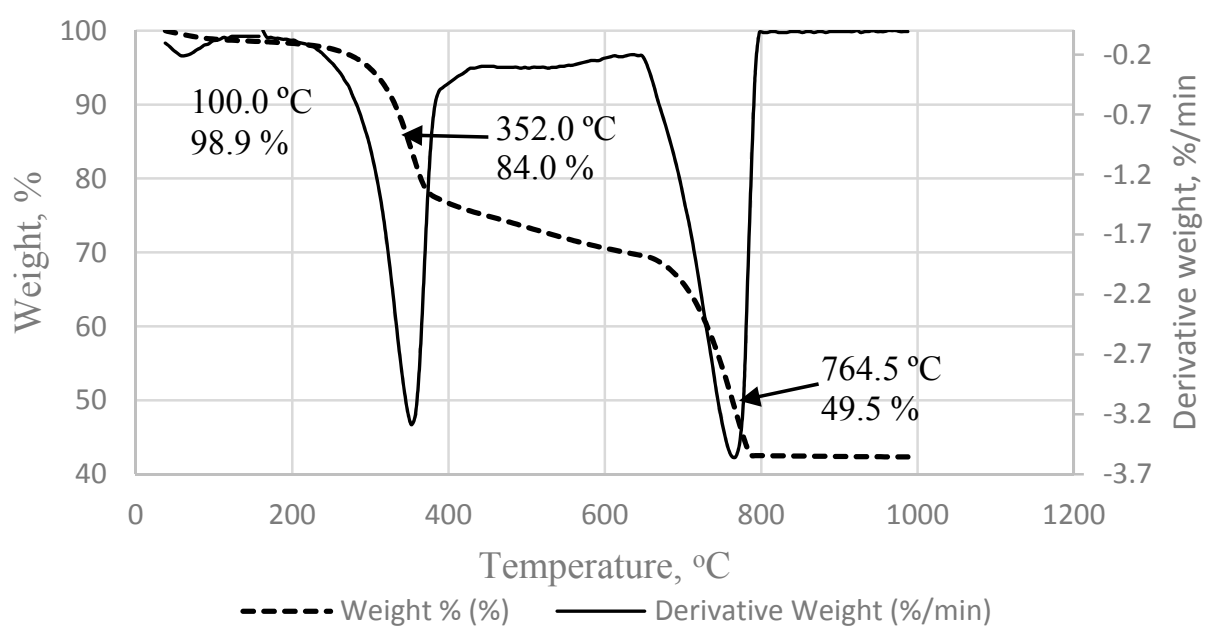

Figure 1. Thermal analysis of PSw.

In the cement paste mixtures formed of the above-described raw materials, $2.5 \%, 5 \%, 7.5 \%$ and $10 \%$, by weight of cement were replaced with PSw. The ratio between water and solid substances was 0.35 .

The X-ray diffraction (XRD) analysis of the phase composition of materials was carried out by using a diffractometer, DRON-7. The compressive strength of the $40 \times 40 \times 40 \mathrm{~mm}$ specimens after their hardening in water for 7 and 28 days was established upon using hydraulic press ALPHA3$3000 \mathrm{~S}$. Strength results were the averages of 4 tested specimens and are presented as percentage strength relative to the control cement paste with the strength activity index (SAI) reported as

$$
\mathrm{SAI}=\mathrm{A} / \mathrm{B}^{*} 100 \% \text {, }
$$

where $A$ is the unconfined compressive strength of the tested pozzolanic specimen (MPa) and B is the unconfined compressive strength of the control specimen (MPa) [10]. 


\section{Results and Discussion}

Density results of specimens with PSw showed that the density of cement samples reduced uniformly with the addition of PSw. The results of the SAI (Figure 2) were determined based on a special methodology and clearly illustrated PSw pozzolanic properties. When up to $5 \%$ of cement was replaced by PSw, the compressive strength of the specimens increased, but replacing $10 \%$ of cement with PSw retained only $80 \%$ compressive strength compared to control specimen.

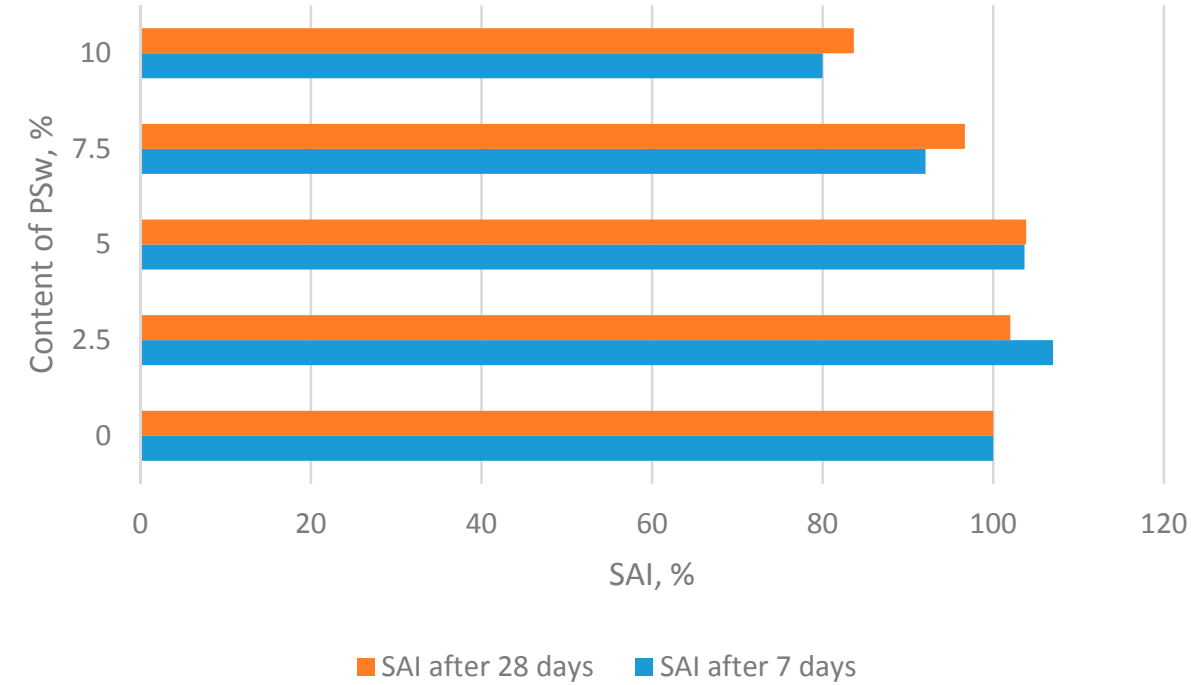

Figure 2. Strength activity index (SAI) dependence on PSw content.

The peak intensities of the base materials (XRD), according to which the amount of analyzed minerals can be determined, are presented in Table 2. The XRD results showed that adding $7.5 \%$ PSw to the cement mixtures compared with samples with $2.5 \%$ PSw increased the amount of portlandite $(\sim 16 \%)$, while ettringite $(\sim 6 \%)$, alite $(\sim 10 \%)$, and belite $(5 \%)$ all decreased. Calcite remained very similar, only varying by $\sim 1 \%$. According to these data, $P S w$ accelerated cement hydration by reducing the amount of unreacted cement minerals [11,12].

Table 2. Relative amounts of base minerals based on their intensities.

\begin{tabular}{ccc}
\hline Mineral & Amount at 2.5\% PSw, a. u. & Amount at 7.5\% PSw, a. u. \\
\hline Portlandite & 344.9 & 410.8 \\
\hline Ettringite & 276.4 & 260.6 \\
\hline Calcite & 200.0 & 202.8 \\
\hline Alite & 203.9 & 182.0 \\
\hline Belite & 168.0 & 159.7 \\
\hline
\end{tabular}

\section{Conclusions}

Summarizing the results, it appeared that 5\% PSw was beneficial for the replacement of cement in cementitious materials. The release of $\mathrm{CO}_{2}$ into the environment was reduced by decreasing the amount of cement and the release of methane gas $\left(\mathrm{CH}_{4}\right)$ was reduced when the paper waste decomposed. When $5 \%$ of cement was replaced by PSw, the density of the specimens decreased by $\sim 0.5 \%$ and the SAI after 28 days of hardening increased by $\sim 4 \%$.

XRD analysis showed that PSw accelerated cement hydration. When the amount of PSw increased, the amount of ettringite and unreacted cement minerals (alite and belite) decreased.

Thermal analysis of PSw showed that at $352{ }^{\circ} \mathrm{C}$, the crystal hydrates disintegrated and the connected water was liberated and at $\sim 765{ }^{\circ} \mathrm{C}$, calcium carbonate decomposed to $\mathrm{CaO}$ and $\mathrm{CO}_{2}$. It was determined that burnt PSw significantly changed the mineral composition and structure. 
Author Contributions: V.B. performed the density and strength experiments; J.M. conceived and designed experiments and wrote the manuscript; M.V. wrote the introduction; R.B. performed the XRD experiments and analyzed the data.

Conflicts of Interest: The authors declare no conflict of interest.

\section{References}

1. Eurostat. Energy, Transport and Environment Indicators; Statistical books, Imprimerie Centrale: Luxembourg, 2018; pp. 148-164.

2. Azevedo, A.R.G.; Alexandre, J.; Xavier, G.C.; Pedroti, L.G. Recycling paper industry effluent sludge for use in mortars: A sustainability perspective. J. Clean. Prod. 2018, 192, 335-346. doi:10.1016/j.jclepro.2018.05.011.

3. Martínez-Lage, I.; Velay-Lizancos, M.; Vázquez-Burgo, P.; Rivas-Fernández, M.; Vázquez-Herrero, C.; Ramírez-Rodríguez, A.; Martín-Cano, M. Concretes and mortars with waste paper industry: Biomass ash and dregs. J. Environ. Manag. 2016, 181, 863-873. doi:10.1016/j.jenvman.2016.06.052.

4. Buruberri, L.H.; Seabra, M.P.; Labrincha, J.A. Preparation of clinker from paper pulp industry wastes. J. Hazard Mater. 2015, 286, 252-260. doi:10.1016/j.jhazmat.2014.12.053.

5. Seifi, S.; Sebaibi, N.; Levacher, D.; Boutouil, M. Mechanical performance of a dry mortar without cement, based on paper fly ash and blast furnace slag. J. Build Eng. 2019, 22, 113-121. doi:10.1016/j.jobe.2018.11.004.

6. Ferrándiz-Mas, V.; Bond, T.; García-Alcocel, E.; Cheeseman, C.R. Lightweight mortars containing expanded polystyrene and paper sludge ash. Constr. Build. Mater. 2014, 61, $285-292$. doi:10.1016/j.conbuildmat.2014.03.028.

7. Novais, R.M.; Carvalheiras, J.; Senff, L.; Labrincha, J.A. Upcycling unexplored dregs and biomass fly ash from the paper and pulp industry in the production of eco-friendly geopolymer mortars: A preliminary assessment. Constr. Build. Mater. 2018, 184, 464-472. doi:10.1016/j.conbuildmat.2018.07.017.

8. Saeli, M.; Tobaldi, D.M.; Seabra, M.P.; Labrincha, J.A. Mix design and mechanical performance of geopolymeric binders and mortars using biomass fly ash and alkaline effluent from paper-pulp industry. J. Clean. Prod. 2019, 208, 1188-1197. doi:10.1016/j.jclepro.2018.10.213.

9. Martínez, C.; Cotes, M.; Corpas, F.A. Recovering wastes from the paper industry: Development of ceramic materials. Fuel Proc. Technol. 2012, 103, 117-124. doi:10.1016/j.fuproc.2011.10.017.

10. Donatello, S.; Tyrer, M.; Cheeseman, C.R. Comparison of test methods to assess pozzolanic activity. Cem. Concr. Comp. 2010, 32, 121-127. doi:10.1016/j.cemconcomp.2009.10.008.

11. Weerdt, K.D.; Ben, H.M.; Saout, G.L.; Kjellsen, K.O.; Justnes, H.; Lothenbach, B. Hydration mechanisms of ternary Portland cements containing limestone powder and fly ash. Cem. Concr. Res. 2011, 41, $279-291$. doi:10.1016/j.cemconres.2010.11.014.

12. Kakali, G.; Tsivilis, S.; Aggeli, E.; Bati, M. Hydration products of $\mathrm{C}_{3} \mathrm{~A}, \mathrm{C}_{3} \mathrm{~S}$ and Portland cement in the presence of $\mathrm{CaCO}_{3}$. Cem. Concr. Res. 2000, 30, 1073-1077. doi:10.1016/S0008-8846(00)00292-1. 